\title{
Analysis of Strength of Glass Fibre Composite Leaf Spring Using Finite Element Method
}

\author{
Andoko $^{1, \text { a }}$, Poppy Puspitasari ${ }^{1}$, Avita Ayu Permanasari ${ }^{1}$ \\ ${ }^{1}$ Department of Mechanical Engineering, Faculty of Engineering, Universitas Negeri Malang, Semarang Street No. 5, \\ Malang, East Java, Indonesia \\ Corresponding author : *andoko.ft@um.ac.id
}

\begin{abstract}
Leaf spring, as one of the main components of the suspension system, serves the function of absorbing road shocks and any wheel vibrations, preventing them from being transmitted directly to the vehicle body. Moreover, it can increase the tire traction as well as support the weight of the vehicle and various kinds of external forces. Various studies on the use of composite materials for leaf springs have shown that the strength of composite leaf spring is similar to steel leaf spring with the same load carrying capacity. However, the composite leaf spring has the added advantage of being more lightweight. In fact, composite materials have been preferable for many purposes not only because of its properties but also its lightweight structure and cost effectiveness. The analysis process was carried out using the finite element method by means of ANSYS software to display the output of the analysis being performed. After the output is known, the amount of voltage in conventional, mounted, and progressive spring can be determined. Based on the data analysis, we concluded that conventional straight leaf springs produced a maximum voltage of 653.13 $\mathrm{MPa}$ and maximum deflection of $4367.1 \mathrm{~mm}$. The results of the analysis using the finite element method showed that conventional leaf springs (both straight and not) are considered as the most effective model of leaf spring in terms of the power generated.
\end{abstract}

Copyright @ $\odot$ 2017Journal of Mechanical Engineering Science and Technology

All rights reserved

Keywords: Leaf spring, Glass fibre composite, Finite element method

\section{Introduction}

A composite material is a macroscopic combination of two or more distinct materials merged or blended into a useful material [1]. The composite material can be defined as a system of material composed of a combination of two or more key elements which are macroscopically different in terms of shape and material composition and basically cannot be separated [2].

In general, composite materials consist of reinforcement and matrix. Composite reinforcements generally have low ductility but relatively high rigidity and strength. The main function of reinforcements is to carry the load in the composite system, meaning that the strength of the composite depends on the reinforcement used. The voltage applied to the composite is initially accepted by the matrix and then transferred to the reinforcement; the reinforcement will bear the maximum load. Therefore, the reinforcement must have a higher tensile strength and modulus of elasticity than the matrix [1].

A matrix is a phase in the composite that has the largest part or volume fraction (dominant). Generally, it has high ductility but low rigidity and strength. It also performs the function of transferring voltage to the fibres, forming a coherent bond, covering the surface of the matrix/fibres, protecting the fibres, separating the fibres, untying the bond, and keeping the stability after the manufacturing process. [3].

The ultimate objectives of formulating composites are to improve the mechanical properties or certain specific characteristics, simplify the complex design in manufacturing process, provide flexibility in shape or design at relatively low production cost, and help save weight. The mechanical properties of composites produced by an institution or factory are usually predictable in terms of the matrix and the reinforcement material they involve [4]. Several mechanical properties of the composite which can be predicted are the tensile strength and feasibility as composite materials (composite validity). In the composite system, tensile strength is influenced by the strength of its interface. However, the strength of the interface is difficult to determine because the testing is not simple-due to certain technical factors in making specimens. Regarding polymer/fibre composites, 
the difference in the mixture of matrix elements and types of fibres can cause different adhesive strength, so oftentimes fibre breaks up before it is detached from the matrix [5].

A fibre-reinforced composite is a composite consisting of fibre and matrix. The primary function of fibres is to carry the load of the composite, meaning that the strength of the composite depends on the fibres used. The voltage applied to the composite is initially accepted by the matrix and then forwarded to the fibres; the fibres will bear the maximum load. Therefore, the fibres must have a higher tensile strength and modulus of elasticity than the matrix. The selection of fibre or reinforcement in the composite system should comply with several things associated with the types of composites, continuous fibre-reinforced composite, woven fibre-reinforced composite, short random fibre-reinforced composite, and continuous random fibre-reinforced composite.

Each glass fibre has its own different characteristics and purposes. Glass fibre is composed of silica, alumina, lime, magnesia and others. Its superiority lies in the price and performance ratio, i.e. low production cost and the ease of production. Glass fibre has been widely used in automotive industries such as vehicle body panels. In fact, the fairings of motorcycles nowadays are made of glass fibre-reinforced composites. Glass-epoxy and glass-polyester composites are also applied for ship hulls and aircraft parts [6].

There are three types of glass fibres, namely E-glass, C-glass, and S-glass. In general, E-glass has a high strength of $350 \mathrm{MPa}$, elongation of $4.8 \%$, a good insulator, and high rigidity, C-glass is resistant to corrosion but less strong and $\mathrm{S}$ glass has a high modulus of elasticity and high temperature resistance [6].

In combining composites and other constituents, i.e. matrix and reinforcement in the form of fibres, there are several factors to ponder. One of the decisive factors affecting the performance of fibre-matrix composites is the fact that the automotive industry requires a relatively large number of metal alloys to produce different parts of a vehicle. Metal replacement seemed like a distant dream back then, but as technology develops, new materials such as glass, polymers, ceramics, synthetic fibres, and some organic and inorganic substances have emerged as a springboard to the development of automotive industry [7]. According to [8], a more interesting aspect is to combine two or more materials one can obtain the mechanical properties of materials better. Composites have improved properties such as high specific strength, stiffness and hardness. In line with the [9] suggests that weight reduction is a key issue in the automotive industry today, as well as the leaf spring suspension system components of the vehicle.

Rear wheel suspension uses leaf spring as a supporting component in the suspension system. Leaf spring mounted below the axle functions as a support for the entire weight of the vehicle including the weight of body, engine, frame, accessories, passenger, and other loads. In addition, it also serves as a shock absorber from any road irregularities and wheel vibrations, and increases the tire traction. However, a spring has limited strength to carry the workload, thus a scientific analysis needs to be carried out to design a leaf spring which has a strong and secure construction.

In this study, the analysis was done by conducting an experiment on the shape of fibreglass/epoxy. The changing of shape affected stress concentration occurring in the leaf spring. This value correlates favourably with [10] suggesting that changing leaf spring's shape and thickness can reduce the occurring voltage.

A previous study has found that even though the leaf spring made of composite materials has a similar strength to the one made of steel with the same workload, it has the added advantage of being more lightweight. In fact, composite materials have been preferable for many purposes not only because of its properties but also its lightweight structure and cost effectiveness [9].

Many engineers and experts in engineering research (particularly on leaf spring) have shown the apparent success of using finite element method in their studies; hence this method is widely used. [6], in his study entitled Performance Analysis of Carbon Fibre with Epoxy Resin Based Composite Leaf Spring, suggested that "the finite element solution show the good correlation for total deformation with analytical results". In a study entitled Mono Composite Leaf Spring for Light Weight Vehicle-Design, End Joint Analysis and Testing, The analytical results were compared with FEA and the results show good agreement with the results. Moreover, [11] further pointed out that "vehicle dynamics stability and overall suspension design parameters have been verified by using finite element analysis and running vehicle on the road, the system was having approximate cost 
saving of $10 \%$ and the system has been implemented on the vehicle successfully"; it was stated in his study Design of Leaf Spring Rear Suspension for Rear Mounted Engine.

A leaf spring is in the form of a flat plate with a certain width and subjected to a lateral load causing the plate to bend [12]. As a component of the suspension system, leaf spring performs the function of absorbing shocks and vibrations in a vehicle, increasing the tire traction, and carrying the weight of the vehicle and its load. According to [13], there are three basic types of leaf spring, i.e. multi-leaf spring, mono-leaf spring, and fibre composite leaf spring. Multi-leaf springs consist of flat steel leaves put together and bound using a clip or U-bolt placed in the central part of the structure. Multi-leaf springs consist of a main leaf, extra full-length leaves, and graduated leaves. The main leaf has an eye spring at each end of the leaf. The extra full-length leaves have almost the same length as the main leaf and are placed between the main leaf and graduated leaves. The graduated leaves, which are shorter than the two others, are stacked under the extra full-length leaves [12].

Mono-leaf springs typically consist of simply one steel plate having a curvature along the leaf. Generally, this type of leaf springs has low stiffness, which provides good riding comfort and goods transport. Moreover, it does not have any characteristics of disturbance and static friction as in the multi-leaf spring [14].

Fibre composite leaf springs are usually made of fibreglass layered and bound together with strong resin polyester. Long fibres in fiberglass are filled with resin and fastened together in a coil or it is commonly referred to as a wire winding process. Fibreglass has a lighter weight than steel spring but has almost the same strength. [15] stated that compared to the leaf spring made of steel, composite leaf spring has lower voltage, higher natural frequency, and is approximately $85 \%$ lighter.

\section{Method}

The analysis was carried out by means of ANSYS software which can display the output of the analysis being performed. After the output is known, the amount of bending stress and deflection in the leaf spring can be determined. The procedure in this simulation consists of the following steps:

Modelling: in this stage, the model was manufactured based on the observation and direct measurement of the leaf spring structure of public car transportation. The steps in modelling are as follows: 1). Observing and directly measuring the leaf spring being studied. 2). Taking photos of the leaf spring as a reference in modelling and documentation. 3). Drawing the geometry of the leaf spring based on the images and data obtained. 4). Designing the car leaf spring model in the form of conventional spring, mounted spring, and progressive spring.

Data collection was done through testing and simulation using ANSYS software. The data was obtained from the analysis results of stress and deflection. The parameters included in ANSYS programme was the design of leaf spring, the data of material properties, the geometry of leaf spring, and the assumption about the loading capacity of the leaf spring.

\section{Findings and discussion}

Based on the result obtained from ANSYS, the conventional leaf spring had the maximum deflection of $5484.7 \mathrm{~mm}$. In Figure 1, the maximum deflection was in the red area or on the loading point of the leaf spring. Based on the manual calculation, the conventional leaf spring had the maximum deflection of $1940.8 \mathrm{~mm}$.

In terms of voltage value, the results showed that the conventional leaf spring had the maximum voltage of $687.55 \mathrm{MPa}$. Based on the ANSYS result (Figure 2), it was in the red area or on the fulcrum of the leaf spring. The maximum voltage according to manual calculation was $39.453 \mathrm{MPa}$. 


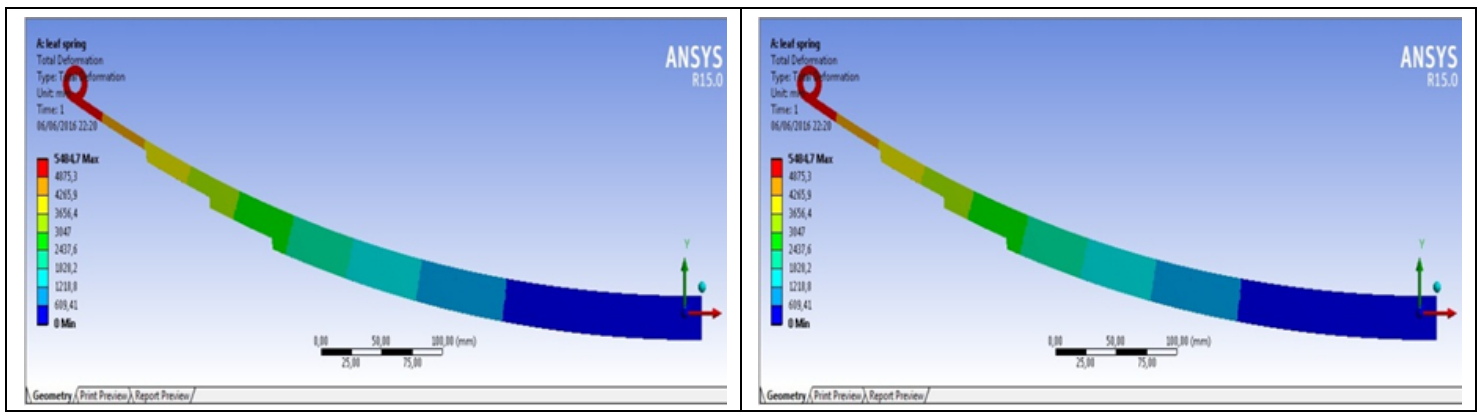

Fig. 1.Analysis Results of Conventional Leaf Spring' Deflection
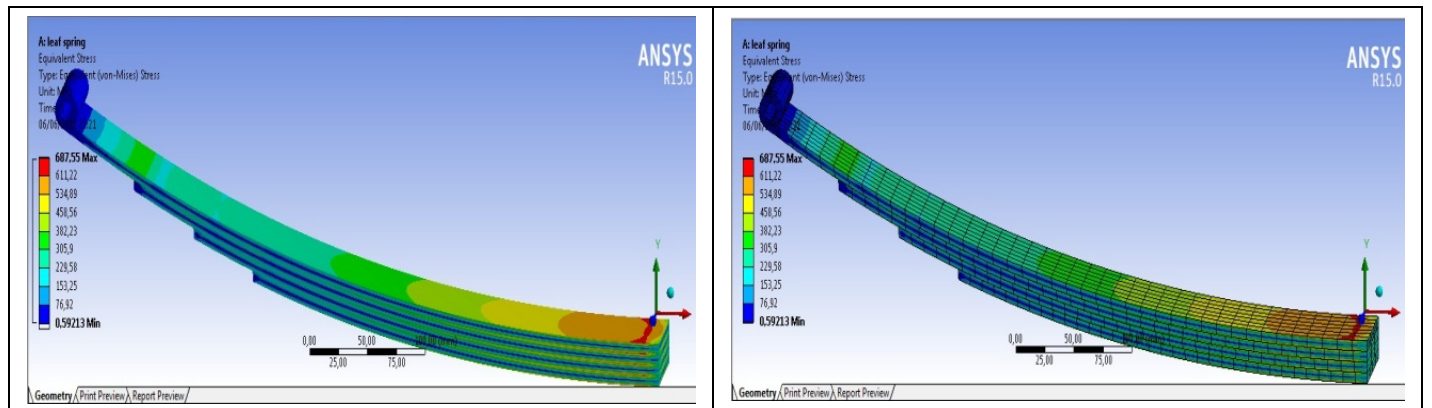

Fig. 2. Analysis Results of Conventional Leaf Spring's Voltage

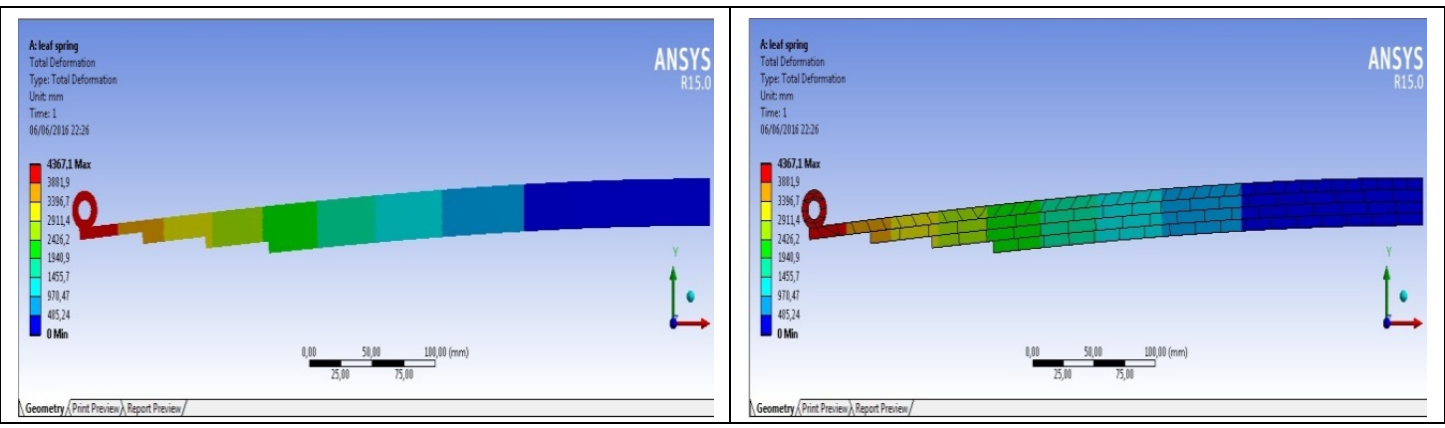

Figure 3. Analysis Results of Conventional Straight Leaf Spring's Deflection
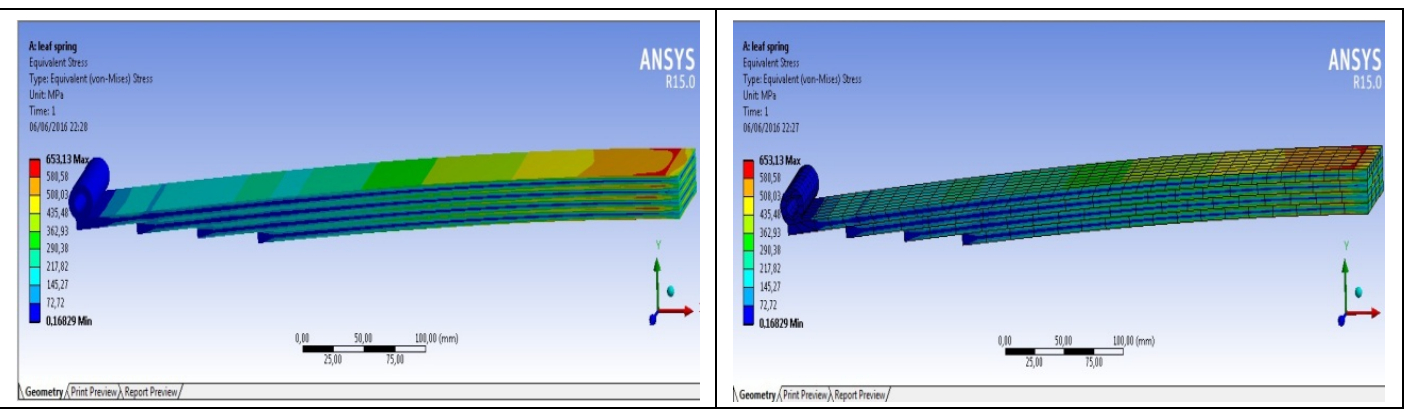

Figure 4. Analysis Results of Conventional Straight Leaf Spring's Voltage

As shown in Figure 3, the conventional straight leaf spring had the maximum deflection of $4367.1 \mathrm{~mm}$ according to ANSYS; it was in the red area or on the loading point of the leaf spring. The result of manual calculation was $1940.88 \mathrm{~mm}$.

The conventional straight leaf spring, based on ANSYS software, had maximum voltage of 653.13 MPa. As shown in Figure 4, it was in the red area or on the fulcrum of the leaf spring. Based on the manual calculation, the maximum voltage was $39.453 \mathrm{MPa}$. 
According to ANSYS, the progressive leaf spring 1 had the maximum deflection of $8020 \mathrm{~mm}$. It was in the red area or on the loading point of the leaf spring (as shown in Figure 5). The result of the maximum deflection according to manual calculation was $1940.88213 \mathrm{~mm}$.

As shown in Figure 6, the progressive leaf spring 1 had the maximum voltage of $1416.7 \mathrm{MPa}$; according to ANSYS, it was in the red area or on the fulcrum of the leaf spring. While the results of manual calculations known maximum voltage of $39.453 \mathrm{MPa}$. Based on the manual calculation, its maximum voltage was 39,453 $\mathrm{MPa}$.

Figure 7 illustrates the maximum deflection of the progressive leaf spring 2 obtained from ANSYS. The maximum value was $8010 \mathrm{~mm}$ and it was in the red area or on the loading point of the leaf spring. The value obtained from manual calculation was $1940.882 \mathrm{~mm}$.

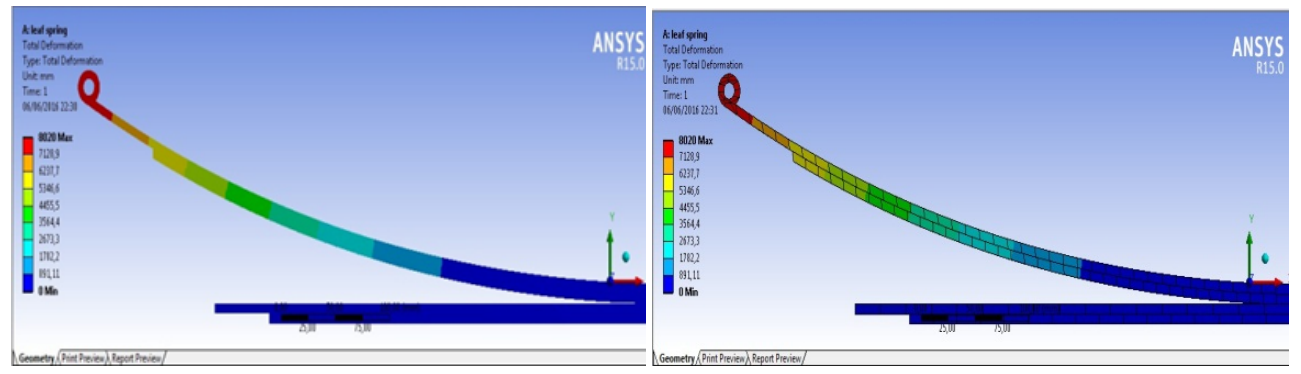

Figure 5. Analysis Results of the Maximum Deflection of Progressive Leaf Spring 1

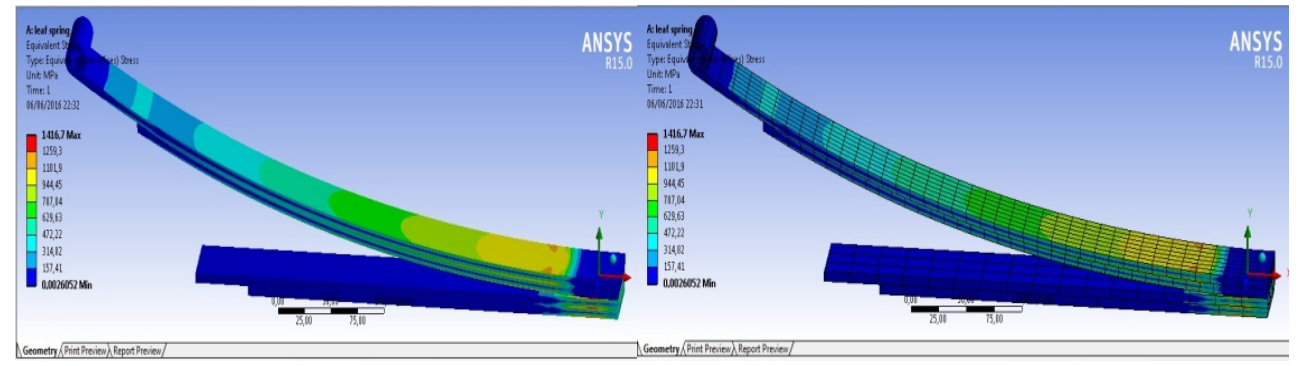

Figure 6. Analysis Results of the Maximum Voltage of Progressive Leaf Spring 1

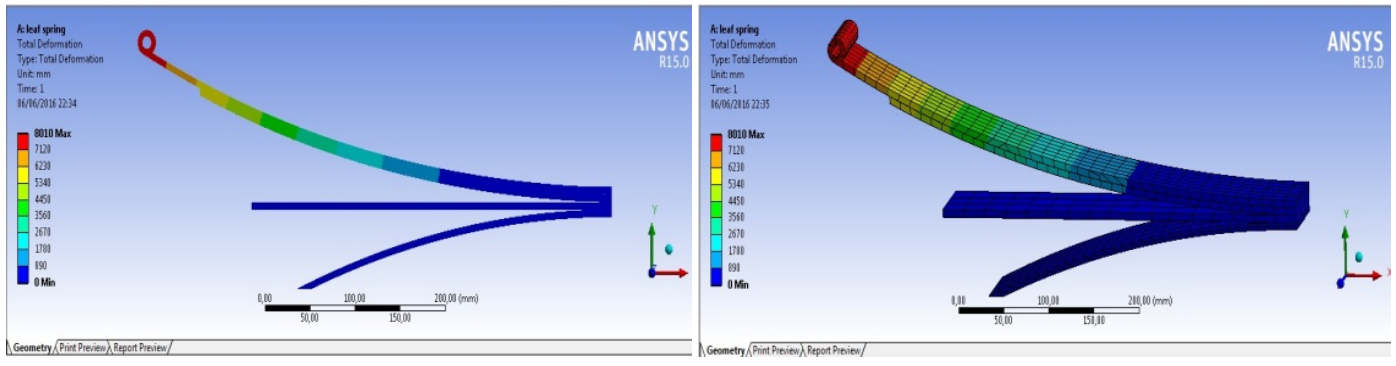

Figure 7. Analysis Results of the Maximum Deflection of Progressive Leaf Spring 2

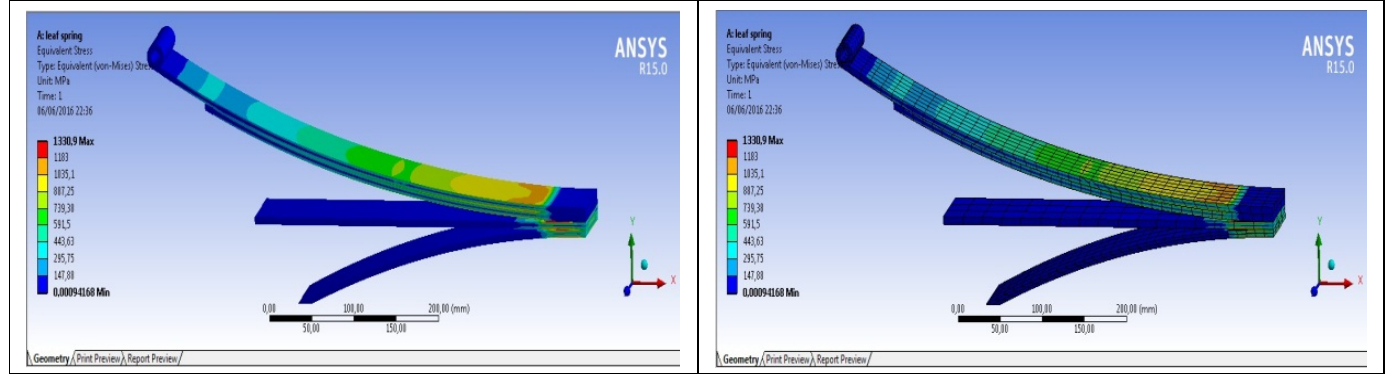

Figure 8. Analysis Results of the Maximum Voltage of Progressive Leaf Spring 2 


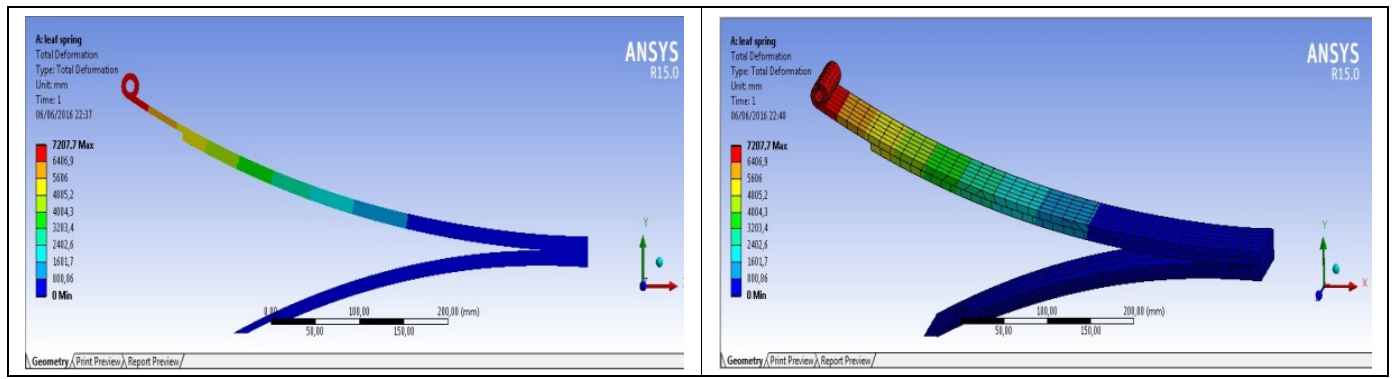

Figure 9. Analysis Results of the Maximum Deflection of Progressive Leaf Spring 3

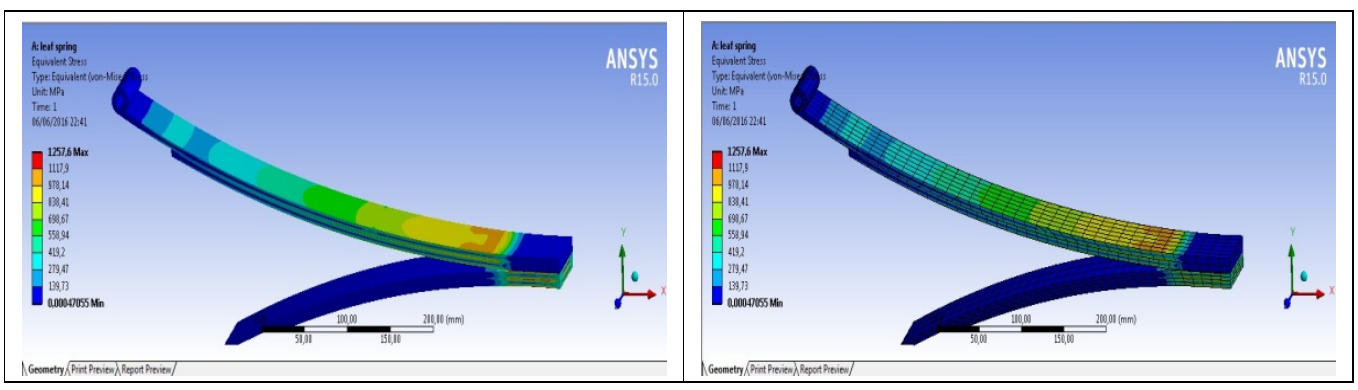

Figure 10. Analysis Results of the Maximum Voltage of Progressive Leaf Spring 3

The maximum voltage of the progressive leaf spring 2 was $1330.9 \mathrm{MPa}$ (obtained from ANSYS). In Figure 8 , it was in the red area or on the fulcrum of the leaf spring. Based on the manual calculation, the maximum voltage was $39.453125 \mathrm{MPa}$.

Figure 9 illustrates the maximum deflection of the progressive leaf spring 3; the maximum deflection was in the red area or on the loading point of the leaf spring. Based on ANSYS analysis, the progressive leaf spring 3 had the maximum deflection of $7270.7 \mathrm{~mm}$. Based on manual calculation; it had the value of $1940.88213 \mathrm{~mm}$.

According to ANSYS software, the maximum voltage of the progressive leaf spring 3 was 1257.6 MPa. As shown in Figure 10, it was in the red area or on the fulcrum of the leaf spring. The maximum voltage based on manual calculation was $39.453125 \mathrm{MPa}$.

The results of the maximum deflection of each of the five types of leaf springs are as follows. The conventional leaf spring had the maximum deflection of $5484.7 \mathrm{~mm}$, the conventional straight leaf spring had the maximum deflection of $4367.1 \mathrm{~mm}$, the progressive leaf spring 1 had the maximum deflection of $8020 \mathrm{~mm}$, the progressive leaf spring 2 had the maximum deflection of 8010 $\mathrm{mm}$, and the progressive leaf spring $3 \mathrm{had}$ the maximum deflection of $7270.7 \mathrm{~mm}$. In other words, the progressive leaf springs 1, with the value of $8020 \mathrm{~mm}$, had the highest maximum deflection among all the five types of leaf springs. In terms of the comparison between the result obtained from ANSYS and manual calculation, the one that had the smallest difference was the conventional straight leaf spring: the value obtained from ANSYS was $4367.1 \mathrm{~mm}$, while the one from manual calculation was $1940.88213 \mathrm{~mm}$.

The following is the results of comparing the maximum voltage of the five leaf springs. The conventional leaf spring had the maximum voltage of $687.55 \mathrm{MPa}$, the conventional straight leaf spring had a value of $653.13 \mathrm{MPa}$, the progressive leaf spring 1 had a value of of $1416.7 \mathrm{MPa}$, the progressive leaf spring 2 had a value of $1330.9 \mathrm{MPa}$, and the progressive leaf springs 3 had a value of of 1257.6 MPa. In brief, among all the five types of leaf springs, the progressive leaf spring 1 had the highest maximum voltage with a value of $1416.7 \mathrm{MPa}$. In terms of the comparison between the result obtained from ANSYS and manual calculation, the one that had the smallest difference was the conventional straight leaf spring, i.e. $653.13 \mathrm{MPa}$ (ANSYS) and $39.453125 \mathrm{MPa}$ (manual calculation).

Referring to Von Mises stress analysis, it showed that the area of maximum voltage is at the leaf spring arm adjacent to the fulcrum. It happened because the fulcrum carried the load uniformly spread along the rod. If a uniformly distributed load is bore upon a rod, or a static load is given to 
each end of a rigid body, then the maximum stress will occur at the fulcrum area. The basic concept of stress, as stated in the theoretical framework, is force divided by cross-sectional area.

The larger the voltage occurs, the lower the security guarantee and the greater the deflection will be. Deflection is the changing position/shape of the material from the original form due to the applied voltage. Therefore, the magnitude of the voltage and loading point affect the amount of deflection that occurs. The greater the voltage, the greater the deflection.

\section{Conclusions}

Among all the five types of leaf springs, progressive leaf spring 1 had the highest maximum voltage of $1416.7 \mathrm{Mpa}$, whereas conventional straight leaf spring had the lowest maximum voltage of 653.13 Mpa.

Progressive leaf spring 1 had the highest maximum deflection with a value of $8020 \mathrm{~mm}$, while conventional straight leaf spring had the lowest maximum deflection with a value of $4367.1 \mathrm{~mm}$.

Among the other types of leaf springs analysed, the testing results of conventional straight leaf spring obtained from ANSYS software was the closest to manual calculation. ANSYS showed that the conventional straight leaf spring had the maximum voltage of $653.13 \mathrm{Mpa}$ and the maximum deflection of $4367.1 \mathrm{~mm}$, while the manual calculation showed that it had the maximum voltage of $39.45 \mathrm{Mpa}$ and the maximum deflection of $1940.88 \mathrm{~mm}$.

According to the test results using ANSYS software, the conventional straight leaf spring and conventional leaf spring were the best to use among all five types of leaf springs.

\section{References}

[1] Jones, P.M. 1975. Mechanics of Composite Material, Institut of Technology, southern ethodist university. Mc.Graw-Hill

[2] Schwartz, 1984. Composite Material Handbook. McGraw-Hill Inc. New York.

[3] Gibson, 1994. Principle of Composite Material Mechanics. Sinagpore. Deparment of Mechanical Engineering Wayne State University Detroid

[4] Callister, 2007. Materials Science and Enginering an Introduction. Ubited State of Amarica Quebeecor Versailes

[5] Rupesh, N. 2015. Design and Analysis of Composite Leaf Spring by Using FEA and ANSYS. International Journal of Scientific Engineering and Research (IJSER), 3 (5): $74-77$.

[6] Ravindra, Parkhe dan Sanjay Belkar. 2014. Perfomance Analysis of Carbon Fibre with Epoxy Resin Based Composite Leaf Spring. International Journal of Current Engineering and Technology. Volume 4 No. 2: $536-541$.

[7] Narayana. 2012. Design and Analysis Of Mono Composite Leaf Spring For Suspension in Automobiles. Int.J. Eng. Res. \& Tech., 1, 6, pp.1-13.

[8] Mehdi and B Majid. 2012. Optimization of SteeHelical Spring by Composite Spring. Int. JMultidisciplinary Sci. Engg., 3, 6, pp. 47-51.

[9] Alwan, Q A Hama and M A Tariq. 2011. The Polymer Composite Beam Reinforced by Natural Jute FibreEngg. Tech. J., 29, 1, pp.1-12.

[10] Regassa, Yohannes, R. Srinivasa dan Ratnam Uppala. 2013. Failure Analysis of Semi-eliptical Master Leaf Spring of Passenger Car Using Element Method. Global Journal of Researches in Engineering Mechanical and Mechanics Engineering. Volume 13 No. 2: 5.

[11] Madane, Vyankatesh, Akshay Baviskar, Anil Gaikwad dan S.S. Sane. 2013. Design of Leaf Spring Rear Suspension for Rear Mounted Engine. SAE International and Symposium on Internatonal Automotive Technology. No.0148: $1-8$.

[12] Hidayat, Taufiq. 2012. Analisa Kegagalan Pegas Daun (Leaf Spring) Pada ToyotKijang Kapsul 7K-EI Tahun 2000. Jurnal Simetris. Volume 1. No. 1: $1-8$.

[13] Erjavec, Jack. 2010. Automotive Tecnology. Clifton Park: Delmar.

[14] Mithari, Ranjet, Amar Patil dan E. N. Aitavade . 2012. Analysis of Composite Leaf Spring by Using Analytical \& FEA. International Journal of Engineering Science and Technology. Volume 4 No. 12: $4809-4814$. 
[15] Nadargi, Yogesh G., Deepak R. Gaikwad dan Umesh D. Sulakhe. 2012. A Perfomance Evaluation Of Leaf Spring Replacing With Composite Leaf Spring. International Journal Of Mechanical and Industrial Engineering. Volume 2 No. 4: $65-68$ 